\title{
An Exploration of the Emergence of Coordinated Domestic Supply Chain for Exotic Vegetables in India: A Case Study of Baby corn
}

\author{
Veena Goel ${ }^{1}$ and Sanica Abbott ${ }^{2 *}$
}

${ }^{1}$ Senior Economist (Marketing) Retd, Department of Economics and Sociology, Punjab Agricultural University, Ludhiana, Punjab, India

${ }^{2}$ Assistant Professor, Amity School of Economics, Amity University, Noida, UP. India

*Corresponding author: sabbott@amity.edu

\begin{abstract}
This study based upon primary data had been carried out to explore the domestic supply chain for baby corn as well as to examine the investment and sales pattern of baby corn of the market agents. The study indicated that the entry of corporate sector in the non-traditional agricultural sector has paved a way for a small segment of the market agents at each level along the commodity specific entire supply chain for an upward mobility. Production thereby of the sales of baby corn was relatively concentrated during the months of October and November. Its average monthly sales from the primary wholesalers were about $14 \%$ higher to the secondary wholesalers in Punjab when compared to West Bengal. Its average monthly sales to the organized sector compared to the traditional retail sector stood $7.51 \%$ higher in the primary wholesale market whereas $33.01 \%$ higher in the secondary wholesale market of Ludhiana city. However, traditional i.e. unorganized retail sector like the sales of seasonal fruits and vegetables also predominates in the sales of this exotic vegetable item. It seems that the sales of this exotic item from the organized retail sector might have been concentrated from particular stores/localities.

JEL classification: Q11, Q13
\end{abstract}

Keywords: Baby corn, supply chain, domestic market, wholesalers, retailers

With the liberalisation and globalisation of Indian economy, corporate sector has carved out a niche market for an export vegetable, namely, baby corn to meet the changing consumption requirements of population with growing incomes (Goel, 2012). However, the number of global players still remain less (Goel and Abbott, 2016). But this has opened up opportunities for the domestic players to build up a coordinated supply chain for this vegetable item in various agro-climatic regions of the country to cater to the middle and upper income market segments in the domestic market. For example, few innovative wholesalers operating from the fruit and vegetable markets in the metropolitan cities such as Delhi, Mumbai, Bangalore etc. have used their existing network for its sourcing i.e. for encouraging their client farmers to allocate some farm areas under its cultivation and also its disposal by enthusing their client wholesalers in the distant markets whereas encouraging the retailers in the local markets to stock this item. As a result, primary, secondary and tertiary wholesalers dispersed over various markets across the regions have come to constitute an essential link between the producers and consumers for the supply of baby corn in the domestic market. Primary wholesalers are located in the regional wholesale markets such as a metropolitan city, secondary wholesalers are located in major cities whereas tertiary wholesalers are in the smaller towns of a state. In the major cities both the traditional and organized retailers have started stocking baby corn (Goel, 2012). As baby corn is an 
exotic item, all the retailers do not stock it. Only the traditional retailers selling from the fixed points and organized grocery stores located particularly in the medium to high income group markets as well as the mobile traditional retailers targeting the medium to high income market segments stock this item.

This study focuses upon the domestic supply chain for baby corn that emerges from primary wholesalers in the Azadpur fruit and vegetable wholesale market, New Delhi. They source unprocessed baby corn directly from producers in the growing areas as well as through the milk cooperative societies from the Punjab state. Farmers and the cooperative societies directly ship baby corn either by themselves to the wholesale market or the wholesalers themselves collect it through shippers from the farms. Secondary wholesalers in the Ludhiana wholesale fruit and vegetable market (Punjab state) purchase baby corn from the primary wholesale market in their own accounts. Tertiary wholesalers operate from the fruit and vegetable wholesale markets of smaller towns such as Moga, Bathinda etc. This study had been carried with the following objectives:

1. To explore the domestic supply chain for baby corn and how it is coordinated

2. To study the investment patterns of the market agents

3. To examine the sales pattern of the market agents

\section{REVIEW OF LITERATURE}

K Shilpa (2008) in her study selected Bangalore city as the study area because of different formats practicing supply chain. Mainly three models of supply chain techniques were selected: traditional, cooperative and modern supply chain. A total of 45 farmers, 4 intermediaries, 15 retail formats and 60 consumers supply chain for the models were selected dealing with 4 vegetables namely tomato, cabbage, carrot and capsicum. Among the sample farmers, highest marketing cost was incurred by farmers in traditional format of the supply chain i.e. ₹ 1.60 per $\mathrm{kg}$ when compared to cooperative and modern supply chain i.e. ₹ 0.83 per $\mathrm{kg}$ and $₹ 0.46$ per $\mathrm{kg}$ respectively. The intermediaries were involved only in the traditional supply chain. Among the retail formats, the cost incurred for a $\mathrm{kg}$ of vegetables by traditional, cooperative modern supply chain was found to be ₹ 1.63 , ₹ 1.01 and ₹ 0.80 , respectively. But the net return for one $\mathrm{kg}$ of vegetables was the highest for cooperative retail format i.e., ₹ 1.90 followed by modern and traditional retail format ₹ 0.79 and $₹ 0.63$ respectively.

Shelke (2009) studied the data on arrivals, prices, marketing costs and marketing margins for the period from June 2007 to May 2008 from APMC, Parbhani, Maharashtra. The vegetables selected were spinach, okra, bean, cabbage, and bitter guard. 26 commission agents and 48 retailers were selected to get the required data. The following broad conclusions were drawn from the study, during the peak period of arrival of these vegetables the wholesale and retail prices were much lower. The margin of retailer was extra ordinarily high in all the vegetables under study. The retailers share ranged between 12 to 41 per cent, while the producer's net share ranged between 42 to 57 per cent. The retailers received lion's share of the consumer's rupee. Producers were highly benefited and increased their share to 95.85 per cent from 55.35 per cent in consumer's price by selling their vegetables directly to consumer rather than by selling it to the wholesalers. Producer arranged to sell their vegetable directly in the consumers market wherever possible.

Singh (2011) studied the value chain of potato in Bihar. It was found that the share of the farmer in the total margin across the value chain of potato was considerably low and the maximum part of the margin was cornered by the intermediaries. In the peak season supply chain, maximum share of the margin was cornered by the wholesaler while the farmer got only a little part especially when the maximum value addition and input cost was borne by the farmer. In the off season, the wholesaler still had the highest margin when compared with the other components in the chain. This margin was significantly lower than the margin in the peak season largely because a significant part of the margin was cornered by the aggregator who sold the produce from the cold storage when the prices were high. The share of farmer in the final retail price of potato was more in peak season (58 per cent) compared with the off season (38 per cent).

Prabhavathi et al. (2013) identified two major supply chains of red chillies in India. In supply chain-I, 
the movement of produce from producer was through trader, wholesaler, retailer and finally to the consumer. In supply chain-II, the produce was purchased from the producer by the processor in regulated market through open auction method. The study revealed that supply chain II was more efficient than the supply chain I because more value goods were delivered to consumer from producer at low marketing costs. The study showed that farmers who brought good quality chillies to market preferred Supply chain-II to supply chain-I. But farmers who brought poor quality, discoloured chillies, preferred supply chain-I.

\section{METHODOLOGY}

There were only five primary wholesalers in the Azadpur fruit and vegetable market, New Delhi who handled baby corn because it has a small market size. A random sample of two primary wholesalers from this market and two secondary wholesalers from the Ludhiana wholesale fruit and vegetable market was taken. A random sample of seven traditional retailers selling from fixed points from the medium to high income group localities was taken from various parts of the city. All the organised grocery stores either did not stock baby corn or were unwilling to divulge with the information. So only two organised grocery stores located in the medium and high income group markets were taken.

Data were collected from the sample wholesalers and retailers relating to their personal and business characteristics, investment patterns, labour use patterns, operational expenses, baby corn sourcing/ purchase and sales pattern to gain insights to the mechanics of domestic market of baby corn. Data for the year 2013 from March to December has been taken for the study. Data from the organized stores could be obtained for the whole year as they have built up a centralised sourcing system directly from the growing areas of several other states.

\section{RESULTS AND DISCUSSION}

\section{Supply chain}

Primary wholesalers handled baby corn along with three/four other exotic or high valued seasonal vegetables. They sourced baby corn directly from farmers of several villages (Haryana) as well as a processing plant (located in Aterna village) in the Sonepat district. Baby corn was dehusked and packed ungraded in small polythene bags of 200 grams at the plant. They had their own arrangements to ship baby corn directly to the wholesale market. Farmers shipped either dehusked baby corn in polythene bags of various sizes or primary wholesalers themselves got it dehusked at the business premises by engaging their own labour during its free time. Baby corn was packed in polythene bags for sales in the local retail market whereas in cartons for safe shipments to distant markets. Primary wholesalers catered to the requirements of the local retail markets as well as distant wholesale markets in other states such as Kolkata in West Bengal, Ludhiana, Jalandhar and Chandigarh in the Punjab state. They sold baby corn in the local markets by both the traditional and organized retailers. Primary wholesalers stored baby corn for two to three days in the cold stores to maintain regularity in the supplies as well as to enhance its shelf-life.

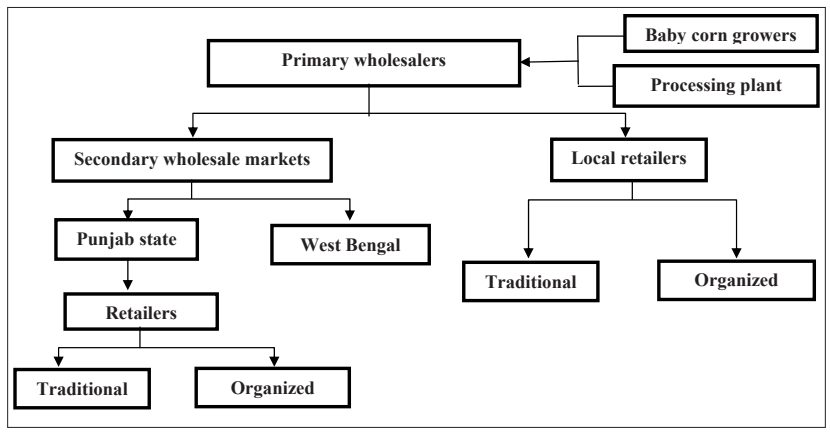

Fig. 1: Domestic supply chain for baby corn

Secondary wholesalers in Ludhiana city handled baby corn along with other exotic and seasonal vegetables such as potatoes. The independently operating shippers helped in shipping baby corn to their business premises. They sold baby corn to the tertiary wholesalers in the smaller cities whereas in the local markets through the traditional and organized retailers.

\section{Respondents' background characteristics}

Table 1 indicates that the average age of the sample primary wholesalers was 47.50 years that stood higher to that for the secondary wholesalers (35.50 years) followed by traditional retailers (34 years) as well as the operators at the organized stores (27.58 years). Average level of schooling in years 
Table 1: Background characteristics of the chain partners

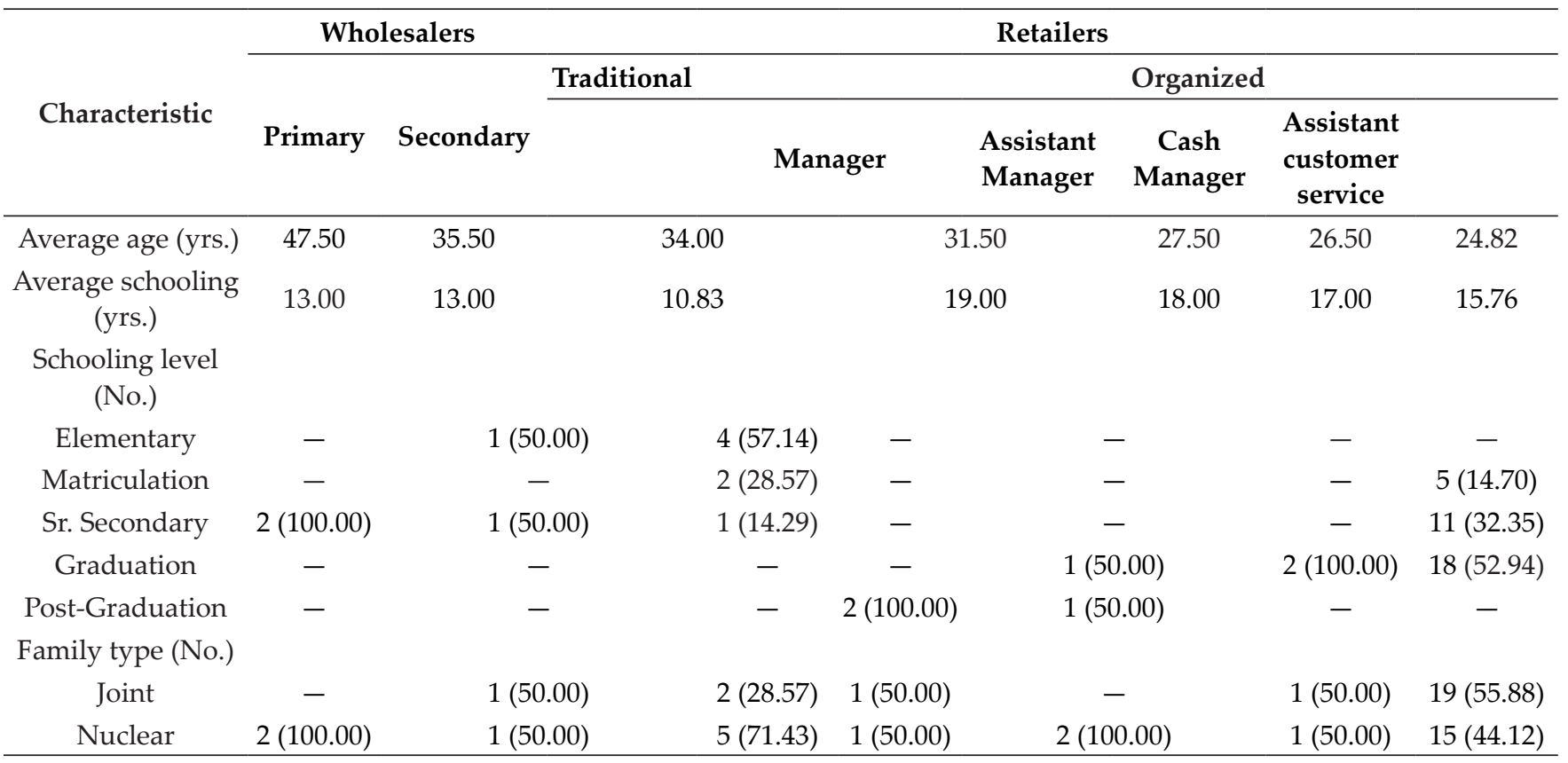

Figures in parentheses indicate percentage

for the wholesalers (primary and secondary) was 13 years but it stood slightly lower for the traditional retailers (10.83 years) whereas higher for the organized retailers (16.10 years). All the primary wholesalers, 50\% secondary wholesalers and $71.43 \%$ traditional retailers had nuclear families. Traditional retailers and primary wholesalers had been in their respective business lines since the 1980s whereas secondary wholesalers had been since the 1990s. And, all the primary wholesalers, 50\% secondary wholesalers and $28.57 \%$ of the traditional retailers had started stocking baby corn during the period 2007-2009; $50 \%$ of the secondary wholesalers and $14.29 \%$ of the traditional retailers during 2009-2011, whereas $57.14 \%$ of the traditional retailers during 2012.

Majority of the sample respondents $(32.50 \%)$ at the organised stores started working since 2011, followed by $25 \%$ during 2010, 20\% during 2009, $12.50 \%$ during 2008 and $10 \%$ during 2012. Average monthly salary at the organized stores for a Manager was ₹ 23,500, and for an Assistant Manager it was ₹ 13,500 . Average monthly wages for labour employed by the primary wholesalers were ₹ 6,800 that stood $4.72 \%$ higher to that hired by secondary wholesalers i.e. ₹ 6,187.50, but it stood much lower for those hired by the traditional retailers i.e. ₹ 3,791.67.

\section{Investment patterns}

Table 2 shows that amongst all the assets at the business premises of the primary and secondary wholesalers as well as traditional retailers, weighing machines accounted for the highest percentage share as $57.92 \%, 52.99 \%$ and $57.25 \%$ respectively. Among the other assets, share of investment on furniture accounted for about $1 / 4^{\text {th }}$ both for the primary and secondary wholesalers; followed by the shares of investment on plastic crates being $11.19 \%$ and $12.33 \%$ for the two. Shares of these two items stood $17.75 \%$ and $6.52 \%$ for the traditional retailers. Major component of investment at the organized stores was on the air conditioner plant that constituted for a share of $32.94 \%$. It was followed by the investment on refrigerators $(21.18 \%)$, racks for stocking food items $(14.12 \%)$, desktops $(9.41 \%)$ and the office equipment $(7.06 \%)$. This share remained below five per cent on trolleys (4.71\%) and baskets (1.18\%).

\section{Operational expenses}

The table 3 depicts that the average monthly rents of the business premises stood the highest for primary wholesalers i.e. ₹ 3,850, followed by traditional retailers i.e. ₹ 3,750 and remained the lowest for secondary wholesalers i.e. ₹ 1,300. Average monthly electricity charges stood highest for primary 
Table 2: Investment patterns of the market agents (Amount-₹)

\begin{tabular}{|c|c|c|c|c|c|c|c|c|}
\hline \multirow{3}{*}{ Asset } & \multicolumn{6}{|c|}{ Wholesalers } & \multirow{2}{*}{\multicolumn{2}{|c|}{$\begin{array}{r}\text { Retailers } \\
\text { Organized }\end{array}$}} \\
\hline & \multicolumn{2}{|c|}{ Primary } & \multicolumn{2}{|c|}{ Secondary } & \multicolumn{2}{|c|}{ Traditional } & & \\
\hline & No. & Amount & No. & Amount & No. & Amount & No. & Amount \\
\hline Weighing machines & 3 & $4500(57.92)$ & 4 & $5500(52.99)$ & 10 & $15800(57.25)$ & - & - \\
\hline Chairs/tables & 6 & $1900(24.45)$ & 7 & $2500(24.08)$ & 15 & $4900(17.75)$ & - & - \\
\hline Plastic crates & 35 & $870(11.19)$ & 52 & $1280(12.33)$ & 68 & $1800(6.52)$ & - & - \\
\hline Tarpaulin & 1 & $500(6.44)$ & 2 & $1100(10.60)$ & 13 & $5100(18.48)$ & - & - \\
\hline $\begin{array}{l}\text { Air conditioner } \\
\text { plant }\end{array}$ & - & - & - & - & - & - & 2 & $1400000(32.94)$ \\
\hline Refrigerators & - & - & - & - & - & - & 9 & $900000(21.18)$ \\
\hline Racks & - & - & - & - & - & - & 80 & $600000(14.12)$ \\
\hline Desktops & - & - & - & - & - & - & 10 & $400000(9.41)$ \\
\hline Office equipment & - & - & - & - & - & - & - & $300000(7.06)$ \\
\hline Trolleys & - & - & - & - & - & - & 30 & $200000(4.71)$ \\
\hline Baskets & - & - & - & - & - & - & 100 & $50000(1.18)$ \\
\hline Misc. & - & - & - & - & - & - & - & $400000(9.41)$ \\
\hline Total cost* & - & 7770 & - & 10380 & - & 27600 & - & 4250000 \\
\hline
\end{tabular}

Figures in parentheses indicate percentages; *Data pertains to 2 primary wholesalers, 2 secondary wholesalers, 7 traditional retailers and 2 organized retailers in totality.

wholesalers (₹ 3,600), followed by secondary wholesalers (₹ 1,125) and traditional retailers (₹ 585.71). Primary wholesalers paid the cold storage charges@ ₹ 2 per kg whereas secondary wholesalers @ ₹ 1 per kg. Secondary wholesalers and the organized retailers transportation charges from Delhi to Ludhiana stood ₹ 156.25 and ₹ 178.45 per quintal whereas traditional retailers transportation charges from the wholesale market to the retail premises stood ₹ 57.14 per quintal. Expenses on the packaging material i.e. polythene bags were ₹ 8 per quintal for the primary and secondary wholesalers and ₹ 10 per quintal for the traditional retailers whereas ₹ 1.02 per bag for organized retailers. Primary wholesalers also paid market fee of $1 \%$.

\section{Monthly sales patterns}

Perusal of table 4 indicates that the sample primary wholesalers total quantity of baby corn sold for ten months during 2013 stood 18720 kgs. Average monthly sales were $1872 \mathrm{kgs}$. that indicated variations of $36.29 \%$ around the mean. Its share stood highest for the month of October (14.96\%) and lowest for the month of December (5.34\%). Among the remaining eight months, its share stood above $10 \%$ for five months, namely, March, April, July,
August and November whereas it ranged from 5\% to $10 \%$ for three months, namely, May, June and September.

Secondary wholesalers total quantity of baby corn sold during the same period stood $5597 \mathrm{kgs}$. Its average monthly quantity was $559.70 \mathrm{kgs}$ that indicated $43.29 \%$ variations around the mean i.e. slightly higher than that of the primary wholesalers. Its share stood highest for the month of October $(16.47 \%)$ and lowest in the month of March (4.47\%). Among the remaining eight months, its share stood above $10 \%$ for four months, namely, April, July, August and November whereas it ranged from $5 \%$ to $10 \%$ for four months, namely, May, June, September and December.

Traditional retailers total quantity of baby corn sold in Ludhiana city during the same period stood $889.20 \mathrm{kgs}$ whereas the average monthly quantity was $88.92 \mathrm{kgs}$ that indicated $43.89 \%$ variations around the mean. Organized retailers total quantity of baby corn purchased during the year was 70 kgs whereas the quantity sold was $66.89 \mathrm{kgs}$ that indicated wastage of $3.11 \mathrm{kgs}$. Monthly share in total sales of baby corn for traditional retailers stood highest for the month of November (17.21\%) and lowest for the month of September (5.06\%). In 
Table 3: Operational expenses of the market agents (Amount-₹)

\begin{tabular}{ccccc}
\hline Item & \multicolumn{2}{c}{ Wholesalers } & \multicolumn{2}{c}{ Retailers } \\
\cline { 2 - 5 } & Primary & Secondary & Traditional & Organized \\
\hline Monthly Charge & & & & \\
\hline Store rent & 3850.00 & 1300.00 & 3750.00 & 88000.00 \\
Electricity charges & 3600.00 & 1125.00 & 585.71 & 80000.00 \\
Market fees & 795.60 & - & - & - \\
Cold storage* (per kg) & 2.00 & 1.00 & - & - \\
\hline Volume based per quintal & & & & 178.45 \\
Transportation costs & - & 156.25 & 57.14 & $1.02^{* * *}$ \\
Polythene bags & 8.00 & 8.00 & 10.00 & - \\
Carton boxes & 12.00 & 12.00 & 12.00 & - \\
\hline
\end{tabular}

*for 2-3 days; ** per bag

contrast, for organized retailers it stood highest for the month of September (17.06\%) and lowest for the month of January (1.49\%). Among the remaining eight months its share for the traditional retailers stood above $10 \%$ for August and October whereas it ranged from $5 \%$ to $10 \%$ for six months, namely, March, April, May, June, July, and December. On the other hand, its share for the organized retailers stood above 10\% for June and August; ranged from $5 \%$ to $10 \%$ for six months, namely, February, March, April, July, October and November whereas it remained up to $5 \%$ for January and May.

\section{Baby corn disposal patterns of wholesalers}

Primary wholesalers total quantities of baby corn disposed through the secondary wholesalers in several markets in the Punjab state and Kolkata market in West Bengal whereas in the local market through the traditional and organized retailers stood $8060 \mathrm{kgs}, 7070 \mathrm{kgs}, 1730 \mathrm{kgs}$ and $1860 \mathrm{kgs}$ that constituted $43.05 \%, 37.77 \%, 9.24 \%$ and $9.94 \%$ shares, respectively. Its average quantities disposed in the three markets stood $806 \mathrm{kgs}, 707 \mathrm{kgs}$ and 179.50 kgs (traditional retailers-173 kgs and organized retailers $-186 \mathrm{kgs}$ ) that indicated variations of $36.54 \%, 36.62 \%$ and $41.60 \%$ around the respective means. Its monthly share in Kolkata market stood highest during the month of October (15.84\%), Punjab state markets during the months of October and November (13.65\% each) whereas in the local market for traditional retailers during the month of October $(17.34 \%)$ and organized retailers during the month of November (16.13\%).

Secondary wholesalers total quantities of baby corn disposed through the tertiary wholesalers, traditional retailers and organized retailers in the local market stood $3225 \mathrm{kgs}, 1018 \mathrm{kgs}$ and $1354 \mathrm{kgs}$ that constituted $57.62 \%, 18.19 \%$ and $24.19 \%$ shares respectively. Its average monthly quantity in the tertiary wholesale markets was $322.50 \mathrm{kgs}$ whereas in the local market it was $118.60 \mathrm{kgs}$ (traditional retailers-101.80 kgs and organized retailers-135.40

$\mathrm{Kgs}$ ) that indicated variations of $48.01 \% 40.15 \%$ and $35.66 \%$ around the respective means. Its monthly share stood highest during the month of October $(16.40 \%)$ for organized retailers whereas during the month of November both for traditional retailers $(15.23 \%)$ and tertiary wholesalers $(17.67 \%)$.

\section{Profit margin}

Primary wholesalers purchased unhusked baby corn from farmers @ ₹ 16/kg whereas dehusked baby corn was purchased from the processing unit@ @ 85/kg. As the former was dehusked at the business premises it also provided them green fodder that could be sold, however, they had to bear the labour costs for its processing. In addition, they handled only three to four items so they also had to bear the fixed cost expenses for stocking this item. Due to non-availability of detailed data of the stocking patterns of various items it had been roughly assumed to be @ ₹ 5/kg. So primary wholesalers gain from baby corn stocking were @ ₹ $20 / \mathrm{kg}$. Along with baby corn, secondary wholesalers as well as retailers handled a number of seasonal vegetable items. So they did not have to make additional investments/incur operational and shipment expenses to stock baby corn. However, 
Table 4: Monthly sales pattern of baby corn of the market agents (Quantity-kgs)

\begin{tabular}{|c|c|c|c|c|c|}
\hline \multirow[t]{3}{*}{ Month } & \multicolumn{2}{|c|}{ Wholesalers } & \multicolumn{3}{|c|}{ Retailers } \\
\hline & \multirow[t]{2}{*}{ Primary } & \multirow[t]{2}{*}{ Secondary } & \multirow[t]{2}{*}{ Traditional } & \multicolumn{2}{|c|}{ Organised } \\
\hline & & & & Purchase & Sales \\
\hline January & - & - & - & $1(1.43)$ & $1.00(1.49)$ \\
\hline February & - & - & - & $5(7.14)$ & $4.78(7.15)$ \\
\hline March & $2000(10.68)$ & $250(4.47)$ & $56.00(6.30)$ & $5(7.14)$ & $5.00(7.47)$ \\
\hline April & $2200(11.75)$ & 565 (10.09) & $82.60(9.29)$ & $5(7.14)$ & $4.94(7.39)$ \\
\hline May & $1200(6.41)$ & $542(9.68)$ & $81.00(9.11)$ & $2(2.86)$ & $1.95(2.92)$ \\
\hline June & $1100(5.88)$ & $285(5.09)$ & $62.00(6.97)$ & $9(12.86)$ & $8.66(12.95)$ \\
\hline July & $2220(11.86)$ & $667(11.92)$ & $74.40(8.37)$ & $5(7.14)$ & $5.00(7.47)$ \\
\hline August & $2500(13.35)$ & $702(12.54)$ & $121.40(13.65)$ & $8(11.43)$ & $7.49(11.20)$ \\
\hline September & $1200(6.41)$ & $380(6.79)$ & $45.00(5.06)$ & $12(17.14)$ & $11.41(17.06)$ \\
\hline October & $2800(14.96)$ & $922(16.47)$ & $150.80(16.96)$ & $6(8.57)$ & $5.62(8.40)$ \\
\hline November & $2500(13.35)$ & $914(16.33)$ & $153.00(17.21)$ & $7(10.00)$ & $6.44(9.63)$ \\
\hline December & $1000(5.34)$ & $370(6.61)$ & $63.00(7.09)$ & $5(7.14)$ & $4.61(6.89)$ \\
\hline Total & 18720 & 5597 & 889.20 & 70 & 66.89 \\
\hline \multirow{2}{*}{ Average } & 1872 & 559.70 & 88.92 & 5.83 & 5.57 \\
\hline & 36.29 & 43.29 & 43.89 & 50.58 & 49.81 \\
\hline
\end{tabular}

Figures in parentheses indicate percentages and bold figures represent values of C.V

Note: The sample for primary wholesalers (2) was taken from Azadpur market, Delhi and they were distributing baby corn to several states from Azadpur market. The sample of secondary wholesalers (2) was taken from Ludhiana wholesale market and they were distributing baby corn as well other vegetables to Ludhiana retailers and adjoining cities. The traditional retailers (7) bought their produce of baby corn from secondary wholesalers and sold it in the local market. The organised retailers sourced their baby corn from a central agency in Haryana. The data for primary, secondary, traditional and organised retailers are independent of each other as none of the wholesalers were willing to share their complete figures. Figures shown for secondary and traditional wholesalers is a small fraction of the figures shown for primary wholesalers.

Table 5: Break up of wholesalers' monthly disposal patterns of baby corn (Quantity-kgs)

\begin{tabular}{|c|c|c|c|c|c|c|c|}
\hline \multirow{3}{*}{ Month } & \multicolumn{4}{|c|}{$\begin{array}{l}\text { Primary wholesalers } \\
\end{array}$} & \multicolumn{3}{|c|}{ Secondary wholesalers } \\
\hline & \multicolumn{2}{|c|}{ Secondary wholesalers } & \multicolumn{2}{|c|}{ Retailers } & \multirow{2}{*}{$\begin{array}{c}\text { Tertiary } \\
\text { wholesalers* }\end{array}$} & \multicolumn{2}{|c|}{ Retailers } \\
\hline & Punjab & Kolkata & Traditional & Organized & & Traditional & Organized \\
\hline March & 900 (11.17) & $800(11.32)$ & $160(9.25)$ & $140(7.53)$ & $150(4.65)$ & $48(4.72)$ & $52(3.84)$ \\
\hline April & $1000(12.41)$ & $900(12.73)$ & $150(8.67)$ & $150(8.06)$ & $315(9.77)$ & $95(9.33)$ & $155(11.45)$ \\
\hline May & $550(6.82)$ & $450(6.36)$ & $100(5.78)$ & $100(5.38)$ & $310(9.61)$ & $98(9.63)$ & $134(9.90)$ \\
\hline June & $450(5.58)$ & $400(5.66)$ & $120(6.94)$ & $130(6.99)$ & $130(4.03)$ & $65(6.39)$ & $90(6.65)$ \\
\hline July & $1000(12.41)$ & $800(11.32)$ & $200(11.56)$ & $220(11.83)$ & $365(11.32)$ & 130 (12.77) & $172(12.70)$ \\
\hline August & $1070(13.28)$ & 900 (12.73) & $250(14.45)$ & $280(15.05)$ & 415 (12.87) & $122(11.98)$ & 165 (12.19) \\
\hline September & $470(5.83)$ & $450(6.36)$ & $120(6.94)$ & $160(8.60)$ & $210(6.51)$ & $80(7.86)$ & $90(6.65)$ \\
\hline October & $1100(13.65)$ & $1120(15.84)$ & 300 (17.34) & $280(15.05)$ & $550(17.05)$ & $150(14.73)$ & $222(16.40)$ \\
\hline November & $1100(13.65)$ & $850(12.02)$ & $250(14.45)$ & $300(16.13)$ & 570 (17.67) & 155 (15.23) & 189 (13.96) \\
\hline December & $420(5.21)$ & $400(5.66)$ & 80 (4.62) & $100(5.38)$ & $210(6.51)$ & 75 (7.37) & $85(6.28)$ \\
\hline Total & $8060(43.05)$ & $7070(37.77)$ & $1730(9.24)$ & $1860(9.94)$ & $3225(57.62)$ & 1018 (18.19) & 1354 (24.19) \\
\hline \multirow{2}{*}{ Average } & 806 & 707 & 173 & 186 & 322.50 & 101.80 & 135.40 \\
\hline & 36.54 & 36.62 & 42.65 & 41.58 & 48.01 & 40.15 & 35.66 \\
\hline
\end{tabular}

*includes Amritsar, Jalandhar, Moga and Bhatinda; figures in parentheses indicate percentages; bold figures represent values of C.V. 
Table 6: Unit prices and profit margin of baby corn of the market agents $(₹ / \mathrm{kg})$

\begin{tabular}{ccccc}
\hline & \multicolumn{2}{c}{ Wholesalers } & \multicolumn{2}{c}{ Retailers (Ludhiana) } \\
\cline { 2 - 5 } Unit price/ Market agent & Primary & Secondary & Traditional & Organized \\
\hline Purchase & 85.00 & 108.50 & 131.42 & 121.25 \\
Sale & 105.00 & 122.50 & 155.71 & 150.80 \\
Gains & 20.00 & 14.00 & 24.29 & 29.55 \\
Operational costs & $7.20^{*}$ & 2.76 & 0.79 & 2.80 \\
Profit margin & 12.80 & 11.24 & 23.50 & 26.75 \\
\hline
\end{tabular}

*includes $₹ 5$ as fixed costs

Note: The purchase price and sale price has been taken as the averages of the prices being reported by individual sample respondents. Gains $=$ Sale price - Purchase Price. Operational costs expenses include transportation costs, costs of polythene bags, carton boxes and cold storage costs. Profit = Gains - Operational costs.

stocking of baby corn provided a single stop shopping opportunity to their client customers. As a result, difference in the unit purchase and sales prices for these market agents may be taken as the profit margins. It stood comparatively much higher for retailers-organized retailers ( $₹ 29.55 / \mathrm{kg}$ ) and traditional retailers ( $₹ .24 .29 / \mathrm{kg}$ ) compared with secondary wholesalers i.e. ₹ $14 / \mathrm{kg}$. Profit margins of the primary and secondary wholesalers stood ₹12.80 per $\mathrm{kg}$ and $₹ 11.24$ per $\mathrm{kg}$ whereas for organized and traditional retailers ₹ 26.75 per $\mathrm{kg}$ and ₹ 23.50 per $\mathrm{kg}$ respectively.

\section{CONCLUSION}

Study indicated that the entry of corporate sector in the non-traditional agricultural sector has paved a way for an upward mobility for a miniscule segment of the various market agents along the commodity specific entire supply chain. And in a particular agro climatic zone its benefits seem to have percolated over a vast geographical area through forward and backward linkages. This is because a coordinated supply chain among the existing chain partners based upon mutual trusts seems to have enhanced the confidence of the upstream chain partners i.e. farmers to allocate some farm land area to the high value crop whereas it has encouraged the downstream chain partners in the distant markets to stock this item without making additional investments.

However, production thereby disposal of baby corn was relatively more concentrated during the months of October and November (when temperature is moderate that is conducive for its growth). Average monthly sales of baby corn from the primary wholesale market were about $14 \%$ higher to the secondary wholesale market of Punjab state when compared to West Bengal. Average monthly sales to the organized retail sector stood $7.51 \%$ higher compared to the traditional retail sector in the primary wholesale market whereas it stood $33.01 \%$ higher in the secondary wholesale market of Ludhiana city. However traditional retail sector like the sales of various seasonal fruits and vegetables also predominates in the sales of this exotic vegetable item. It seems that the sales of an exotic item like baby corn from the organized retail sector might had been concentrated from particular stores/localities.

\section{REFERENCES}

Abbott, S. 2016. Integrated Supply Chain Management for Baby corn in Punjab state. Ph.D. thesis submitted to Punjab Agricultural University, Ludhiana, Punjab.

Goel, V. 2012. Linking Farmers in India with Global Markets: A Case Study of Export Chains for Exotic Vegetables from Punjab state. available at www.ifama.org

Goel V. and Abbott, S. 2016. An Emerging Scenario of the Exports Pattern of Exotic Vegetable from India- A Case Study of Baby corn. International Journal of Social Science and Development Policy, 2(1): 7-19.

Prabhavathi, Y., Kishore, K.N.T. and Seema 2013. Analysis of supply chain of spices in India: A case study of red chillies. Int. J. Sci. Res. Publication, 3: 1-4.

Shelke, R.D. 2009. Economics of price spreads in marketing of major vegetable in Parbhani market. Econ Affair, 54: 3-4.

Shilpa, K. 2008. Supply chain management in vegetables marketing. M.Sc thesis, University of Agricultural Sciences, Dharwad, Karnataka.

Singh, S. 2011. Farm to fork supply chain of potato in the state of Bihar. CCS Working paper no.25. Centre for Civil Society. 